\title{
AIAA
}

\section{AIAA 2002-3332}

Heat Transfer in High-Temperature Fibrous Insulation

Kamran Daryabeigi

NASA Langley Research Center

Hampton, VA

\section{$8^{\text {th }}$ AIAA/ASME Joint Thermophysics and Heat Transfer Conference 24-26 June 2002 / St. Louis, MO}

For permission to copy or to republish, contact the copyright owner named on the first page.

For AIAA-held copyright, write to AIAA Permissions Department,

1801 Alexandria Bell Drive, Suite 500, Reston, VA, 20191-4344 
AIAA 2002-3332

\title{
HEAT TRANSFER IN HIGH-TEMPERATURE FIBROUS INSULATION
}

\author{
Kamran Daryabeigi* \\ NASA Langley Research Center \\ Hampton, Virginia 23681
}

\begin{abstract}
$\underline{\text { Abstract }}$
The combined radiation/conduction heat transfer in high-porosity, high-temperature fibrous insulations was investigated experimentally and numerically. The effective thermal conductivity of fibrous insulation samples was measured over the temperature range of $300-1300 \mathrm{~K}$ and environmental pressure range of $1.33 \times$ $10^{-5}-101.32 \mathrm{kPa}$. The fibrous insulation samples tested had nominal densities of 24,48 , and $72 \mathrm{~kg} / \mathrm{m}^{3}$ and thicknesses of 13.3, 26.6 and $39.9 \mathrm{~mm}$. Seven samples were tested such that the applied heat flux vector was aligned with local gravity vector to eliminate natural convection as a mode of heat transfer. Two samples were tested with reverse orientation to investigate natural convection effects. It was determined that for the fibrous insulation densities and thicknesses investigated no heat transfer takes place through natural convection. A finite volume numerical model was developed to solve the governing combined radiation and conduction heat transfer equations. Various methods of modeling the gas/solid conduction interaction in fibrous insulations were investigated. The radiation heat transfer was modeled using the modified two-flux approximation assuming anisotropic scattering and gray medium. A genetic-algorithmbased parameter estimation technique was utilized with this model to determine the relevant radiative properties of the fibrous insulation over the temperature range of 300-1300 K. The parameter estimation was performed by least square minimization of the difference between measured and predicted values of effective thermal conductivity at a density of $24 \mathrm{~kg} / \mathrm{m}^{3}$ and at nominal pressures of $1.33 \times 10^{-4}$ and $99.98 \mathrm{kPa}$. The numerical
\end{abstract}

model was validated by comparison with steady-state effective thermal conductivity measurements at other densities and pressures. The numerical model was also validated by comparison with a transient thermal test simulating reentry aerodynamic heating conditions.

\section{Nomenclature}

$\mathrm{A}=$ fraction of conduction heat transfer in parallel mode

$\mathrm{b}=$ back scattering fraction

$\mathrm{c} \quad=$ specific heat, $\mathrm{J} / \mathrm{kg} / \mathrm{K}$

$\mathrm{D}_{\mathrm{f}}=$ fiber diameter, $\mathrm{m}$

$\mathrm{d}_{\mathrm{g}}=$ gas collision diameter, $\mathrm{m}$

$\mathrm{e} \quad=$ specific extinction coefficient $(\mathrm{e}=\beta / \rho), \mathrm{m}^{2} / \mathrm{kg}$

$\mathrm{F}^{+}=$forward radiative flux, $\mathrm{W} / \mathrm{m}^{2}$

$\mathrm{F}^{-}=$backward radiative flux, $\mathrm{W} / \mathrm{m}^{2}$

$\mathrm{f}=$ solid fraction ratio

$\mathrm{K}_{\mathrm{B}}=$ Boltzmann constant, $1.3806 \times 10^{-23} \mathrm{~J} / \mathrm{K}$

$\mathrm{Kn}=$ Knudsen number

$\mathrm{k}=$ thermal conductivity, $\mathrm{W} / \mathrm{m} / \mathrm{K}$

$\mathrm{L}=$ insulation thickness, $\mathrm{m}$

$\mathrm{L}_{\mathrm{c}}=$ characteristic length, $\mathrm{m}$

$\mathrm{m}=$ solid conduction exponent term

$\mathrm{n}=$ index of refraction

$\mathrm{P}=$ pressure, $\mathrm{Pa}$

$\operatorname{Pr}=$ Prandtl number

$\mathrm{q}=$ heat flux, W/m

$\mathrm{R}=$ root mean square deviation

$\mathrm{S}=$ sum of the squares of deviations

$\mathrm{T}$ = temperature, $\mathrm{K}$

$\mathrm{t}=$ time, $\mathrm{s}$

$\mathrm{x}=$ spatial coordinate, $\mathrm{m}$

$\mathrm{z} \quad=$ parameter for conduction heat transfer model (Eq. 17.e) based on fiber orientation

\footnotetext{
* Aerospace Engineer, Metals and Thermal Structures Branch, Mail Stop 396, Senior Member AIAA.

Copyright $(\underset{0}{ } 2001$ by the American Institute of Aeronautics and Astronautics, Inc. No copyright is asserted in the United States under Title 17, U.S. Code. The U.S. Government has a royalty-free license to exercise all rights under the copyright claimed herein for Governmental Purposes. All other rights are reserved by the copyright owner.
} 


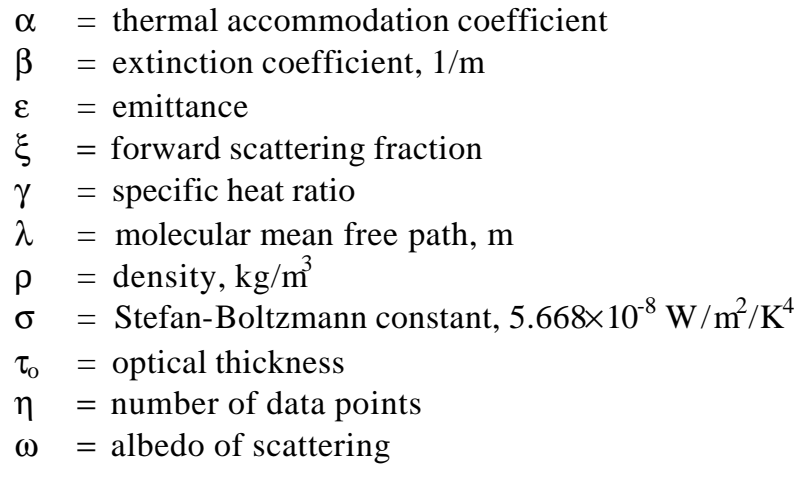

\section{Subscripts}

$\mathrm{e}=$ effective property

$\mathrm{g}=$ gas

$\mathrm{r}=$ radiation

$\mathrm{s} \quad=$ solid

$\mathrm{T}=$ total

$\mathrm{e}-\mathrm{m}=$ measured effective property

$\mathrm{e}-\mathrm{p}=$ predicted effective property

\section{Superscripts}

$* \quad=$ property at atmospheric pressure

$* *=$ property of parent material

\section{Introduction}

The purpose of this work is to investigate heat transfer in high-porosity, high-temperature fibrous insulation subject to temperature and pressure conditions representative of reentry aerodynamic heating for reusable launch vehicles. The fibrous insulation considered in this study is loose fibrous insulation made of alumina, similar to fiberglass insulation used for home insulation, and can be used in metallic thermal protection systems for reusable launch vehicles. The thermal protection system is used to maintain a reusable launch vehicle's structural temperature within acceptable limits during reentry flight. The Space Shuttle orbiter's thermal protection system consists of rigid fibrous insulation ceramic tiles and flexible blankets. Metallic thermal protection systems have been considered for the next generation of reusable launch vehicles. ${ }^{1}$ A metallic thermal protection system consists of a metallic shell panel fabricated from a high-temperature metallic alloy and mechanically attached to the vehicle structure; the shell is filled with lightweight, non-load-bearing loose fibrous insulation.

Heat transfer through a fibrous insulation during atmospheric reentry involves combined modes of heat transfer: solid conduction through fibers, gas conduction in the void spaces between fibers, and radiation interchange through participating media in the fibrous insulation, and possibly natural convection depending on the orientation of the imposed heat flux and the gravity vector. The fibrous insulation is subjected to environmental pressures in the range of $1.33 \times 10^{-5}-101.32 \mathrm{kPa}$, and temperatures in the range of $300-1300 \mathrm{~K}$.

Various formulations for heat transfer through fibrous insulation have been investigated, but most of the models have been validated with experimental results over only a limited pressure and temperature range. Lee and Cunnington ${ }^{2}$ have provided an extensive review of the various analytical formulations used for modeling the radiation component of heat transfer through fibrous insulation. A brief review of some pertinent research is provided. Two distinctly different classes of solutions have been attempted.

In the first class of solutions, the researchers have developed an effective thermal conductivity model based on superposition of gas, solid and apparent radiation thermal conductivities, based on optically thick assump tion, and compared the results with measured effective thermal conductivities of samples subjected to small temperature differences across the insulation thicknesses. Verschoor, et al., ${ }^{3}$ used a gas conduction model valid from the rarefied to the continuum regime, and validated their model by comparison with thermal conductivity measurements over a pressure range of $0.133-101.32 \mathrm{kPa}$ and temperatures up to $340 \mathrm{~K}$. Hager and Steere ${ }^{4}$ neglected solid conduction and used an approximate gas conduction model, and compared their results with experimental results at $300 \mathrm{~K}$ at a pressure range of $1.33 \times 10^{-7}-101.32 \mathrm{kPa}$. They attributed the discrepancy between the measured and predicted values to the presence of natural convection. Bankvall ${ }^{5}$ provided for detailed modeling of the interaction between solid and gas thermal conductivities, and compared his analysis with experimental results obtained at pressures of $1.33 \times 10^{-4}-101.32 \mathrm{kPa}$ and at temperatures up to $350 \mathrm{~K}$. Pawel, et al., ${ }^{6}$ studied rigid insulation and used an effective thermal conductivity based on linear superposition of gas and solid conduction taking place both in parallel and series arrangements. They compared their predictions with experimental results for pressures between 5.332 and $101.32 \mathrm{kPa}$ and temperatures up to $1200 \mathrm{~K}$.

Bhattacharyya ${ }^{7}$ investigated various form of combining solid and gaseous conduction modes.

In the second class of solutions, researchers have calculated approximate analytical or numerical solutions for the heat transfer through insulations. Larkin and Churchill ${ }^{8}$ used a two flux approximation assuming a purely scattering medium to model radiation heat transfer through fibrous insulations. They compared their results with measured optical 
transmission through fibrous insulation samples. Tong, et al., ${ }^{9,10}$ modeled radiation heat transfer through fibrous insulation using the two-flux model assuming a linearized anisotropic scattering, and compared their predicted combined radiant and conduction fluxes with measured data up to $450 \mathrm{~K}$ and at one atmosphere. In Ref. 11 an apparent radiant conductivity based on the diffusion approximation was used in a numerical solution for the combined conduction/radiation heat transfer in fibrous insulations and compared with experimental steady-state effective thermal conductivity measurements over a temperature range of 300-1200 K and pressure range of $1.33 \times 10^{-5}-101.32 \mathrm{kPa}$. In follow-on work, the combined radiation/conduction heat transfer in fibrous insulation spacers between reflective foils of high temperature multilayer insulations was modeled using the two-flux approximation assuming isotropic scattering for the radiation heat transfer. $^{12,13}$ Lee and Cunnington ${ }^{2}$ computed the combined conduction radiation heat transfer in fibrous insulation using an optically thick assumption and anisotropic scattering, and compared their predictions with published experimental results at temperatures up to $800 \mathrm{~K}$ and in vacuum.

Starke and Frick ${ }^{14}$ have stated there is no natural convection in fibrous insulations with densities larger than $20 \mathrm{~kg} / \mathrm{m}^{3}$ because the fibers subdivide the gas into sufficiently small pores. Even though natural convection has generally been ignored as a possible mode of heat transfer in high-porosity fibrous insulations, some researchers ${ }^{3,15}$ have attributed the difference in measured and calculated heat transfer through the insulations to natural convection heat transfer.

The objective of this investigation was to experimentally investigate whether natural convection is a mode of heat transfer in high-porosity fibrous insulations of interest for thermal protection systems, and model the heat transfer through fibrous insulation with a numerical model validated by both steady-state and transient thermal tests. The steady-state tests consisted of measuring the effective thermal conductivity of the fibrous insulation at various densities and thicknesses over an extended temperature and pressure range, $300-1300 \mathrm{~K}$ and $1.33 \times 10^{-5}-101.32$ $\mathrm{kPa}$. The transient tests consisted of subjecting a fibrous insulation sample to simulated reentry aerodynamic heating conditions in a thermal vacuum chamber. The radiation heat transfer was modeled using the modified two-flux method assuming anisotropic scattering. Various forms of modeling gas and solid conduction interaction were investigated. A genetic algorithm based parameter estimation technique was utilized to determine the relevant radiant properties of the fibrous insulation over the temperature range of $300-1300 \mathrm{~K}$. The numerical heat-transfer model was validated by comparison with both steady state and transient thermal measurements.

\section{Experimental Approach}

The fibrous insulation samples used in the study are discussed. Both steady state and transient tests were used for studying the thermal behavior of fibrous insulations and for validating the numerical heat transfer model used in the design study. A brief description of the steady state and transient thermal testing apparatus is provided.

\section{Fibrous Insulation Samples}

The fibrous insulation samples studied in this investigation utilized alumina fibers with a mean fiber strand diameter of $3 \times 10^{-6} \mathrm{~m}$ and a maximum operating temperature of $1900 \mathrm{~K}$. For the present study ten different fibrous insulation samples were tested. A listing of the samples with their respective thicknesses, densities, solid fraction ratios (ratio of insulation density to density of alumina), type of testing, and heat source location relative to the sample is provided in Table 1. Nine samples were used in the steady-steady thermal testing apparatus and had planform dimensions of $203.2 \times 203.2 \mathrm{~mm}$. The samples were 13.3, 26.6 and $39.9 \mathrm{~mm}$ thick. The fibrous insulation considered for the most recent metallic thermal protection system $\operatorname{design}^{1}$ is at a density of $48 \mathrm{~kg} / \mathrm{m}^{3}$, therefore, test samples with densities of $0.5,1$, and 1.5 times this density were chosen, resulting in sample densities of 24,48 , and $72 \mathrm{~kg} / \mathrm{m}^{3}$. Furthermore, the samples were tested in two different heating orientations. For samples 1-7 heat was applied from the top, resulting in the heat flux vector being aligned with the gravity vector. With this orientation there was no natural convection heat transfer through the sample. For samples 8 and 9 heat was applied from the bottom, resulting in the heat flux vector being in the opposite direction of the gravity vector. This orientation was conducive to development of natural convection. Furthermore samples 8 and 9 had the lowest insulation density, thus further enhancing the chance of development of natural convection. Samples 3 and 8 had the same thickness and density but had different heating orientations. Similarly samples 6 and 9 only differed in the heating orientations. Therefore, the comparison of their effective thermal conductivity would determine whether natural convection is a mode of heat transfer in fibrous insulation samples. Sample 10 was used in the transient thermal testing apparatus 
and had dimensions of $304.8 \times 304.8 \mathrm{~mm}$. It had a thickness of $53.3 \mathrm{~mm}$ and a density of $45.1 \mathrm{~kg} / \mathrm{m}^{3}$, and was heated transiently from the top.

\section{Steady-State Thermal Testing Apparatus}

A thermal conductivity apparatus, described in detail in Ref. 13 and 16, was used to measure the steady-state effective thermal conductivity of the fibrous insulation samples. The apparatus used in this study followed the general guidelines from ASTM standard C201 (Ref. 17). This test set-up was not used to measure effective thermal conductivities of the test specimen subject to small temperature differences maintained across the sample as is customary in majority of steady-state thermal conductivity measurement techniques. The main purpose was to use a steady state testing facility for characterization of the thermal performance of the insulation subject to pressures and temperature differences across the sample that would be representative of the conditions experienced during reentry aerodynamic heating conditions (environmental pressures of $1.33 \times 10^{-5}$. $101.32 \mathrm{kPa}$, with temperature differences as high as $1000 \mathrm{~K}$ maintained across the sample thickness). The results are presented as effective thermal conductivity, even though the results could have also been presented as total measured heat flux.

A schematic of the apparatus is shown in Fig. 1. The test specimen was located between a $6.4 \mathrm{~mm}$ thick Inconel septum panel and a $25.4 \mathrm{~mm}$ thick water-cooled aluminum plate, both plates having dimensions of 304.8 $\times 304.8 \mathrm{~mm}$. The water-cooled plate was instrumented with nine thin -film heat-flux gages and ten type-K thermocouples, and the septum panel was instrumented with 23 metal-sheathed type-K thermocouples. The data from the thermocouples and heat flux gages from the central $127 \times 127 \mathrm{~mm}$ section of the test setup were used for calculating effective thermal conductivities.

Ref. 16 provides details on the location of instrumentation on the water-cooled plate and septum plates. A ceramic radiant heater was used for heating and controlling the temperature of the septum plate. Refractory ceramic insulation boards $25.4 \mathrm{~mm}$ thick, were placed around the apparatus to minimize heat losses (not shown in Fig. 1). The effective thermal conductivity of the sample was measured with septum panel temperature set at nominal temperatures between 373 and $1273 \mathrm{~K}$, and with the water-cooled plate maintained around room temperature. The apparatus was located inside a vacuum chamber and the environmental pressure was varied between $1.33 \times 10^{-5}$ and $101.32 \mathrm{kPa}$. All the tests were conducted in a gaseous nitrogen environment. Data were typically obtained with nominal temperature differences of 90 , $260,425,590,760,870$ and $980 \mathrm{~K}$ maintained across the sample thickness and with environmental pressures of $1.33 \times 10^{-5}, 1.33 \times 10^{-4}, 1.33 \times 10^{-3}, 1.33 \times 10^{-2}$, $0.033,0.066,0.133,0.333,0.667,1.33,13.33,99.99$, and $101.32 \mathrm{kPa}$. Not all the samples were tested at all the nominal pressures and temperature differences. The effective thermal conductivity was calculated using the Fourier law of heat conduction using the following measured average parameters: septum panel temperature, $T_{1}$, water-cooled plate temperature, $T_{2}$, and heat flux, $q$, according to:

$$
\mathrm{k}_{\mathrm{e}}=\frac{\mathrm{qL}}{\mathrm{T}_{1}-\mathrm{T}_{2}}
$$

The orientation shown schematically in Fig. 1 was used for testing samples 1-7. For this orientation the heater was located on top of the test sample, therefore, the heat flux vector was aligned with local gravity vector and natural convection was not a mode of heat transfer. To investigate natural convection, the arrangement of the various components in the apparatus was reversed, thus resulting in the heater being at the bottom of the stack-up. For this orientation the heat flux vector was in the opposite direction of the gravity vector, thus being favorable to development of natural convection as a mode of heat transfer.

The average uncertainty of the effective thermal conductivity measurements was $7.5 \%$ over the entire range of pressures and temperatures (details of the uncertainty analysis are provided in Ref. 13).

Measurements on a fumed silica board, Standard Reference Material 1459 from the National Institute of Standard and Technology, at temperatures up to $573 \mathrm{~K}$ were within $5.5 \%$ of published data. ${ }^{13}$

\section{Transient Thermal Testing Apparatus}

A transient thermal test was conducted to simulate reentry aerodynamic heating conditions. The flight trajectory of the NASA winged-body reference vehicle configuration designated 001 (Ref. 18) was used in this study. A plot of the corresponding reentry flight profile is provided in Fig. 2 where the vehicle reentry altitude and velocity variations are shown. The steady-state thermal conductivity apparatus was modified in order to perform the transient thermal test. The heater was changed from a ceramic radiant heater to a low thermalmass quartz lamp radiant heating array in order to be able to provide the rapid changes in heating required for simulating the transient reentry heating profile.

Furthermore, a $304.8 \times 304.8 \times 3.18 \mathrm{~mm}$ aluminum panel instrumented with seven type $\mathrm{K}$ thermocouples was installed in the stack-up between the Inconel panel 
and the water-cooled plate. ${ }^{13}$ A schematic of the transient thermal test apparatus is shown in Fig. 3. The test article (sample 10), a $53.3 \mathrm{~mm}$ thick fibrous insulation sample with a density of $45.1 \mathrm{~kg} / \mathrm{m}^{3}$, was placed between the Inconel and aluminum panels. The Inconel panel served as the hot side solid boundary, while the aluminum panel represented the launch vehicle structure. A $13.3 \mathrm{~mm}$ thick alumina fibrous insulation with a density of $24.3 \mathrm{~kg} / \mathrm{m}^{3}$ was placed between the aluminum panel and the water-cooled plate to represent a heat loss mechanism from the launch vehicle structure attached to the thermal protection system. Typical reentry vehicle design assumes that the launch vehicle structure is adiabatic, but this assumption has been shown to be conservative. ${ }^{19,20}$ Furthermore, it is extremely difficult to maintain an adiabatic boundary condition; any insulation will conduct and absorb some heat. The present apparatus overcomes this difficulty. The measured transient temperatures of the septum panel and water-cooled plate can be used as boundary conditions in the numerical model, and then the comparison of the measured and numerically predicted aluminum panel temperature can be used for validation of the numerical model.

Refractory ceramic board insulation spacers having planform dimensions of $38.1 \times 38.1 \mathrm{~mm}$ were used at the four corners of the test set-up between the watercooled plate and aluminum panel, and between the aluminum and Inconel panels. These spacers were used to maintain the desired thickness of the insulation samples: $13.3 \mathrm{~mm}$ and $53.3 \mathrm{~mm}$ below and above the aluminum panel, respectively. Refractory ceramic insulation boards (not shown in Fig. 3), $25.4 \mathrm{~mm}$ thick, were placed around the apparatus to minimize heat losses.

The Inconel panel's temperature was controlled to simulate the transient radiative equilibrium temperatures ${ }^{21}$ corresponding to the reentry flight profile shown in Fig. 2. The pressure in the vacuum chamber was also varied in order to simulate pressures corresponding to the reentry flight profile shown in Fig. 2. The radiative equilibrium temperature and pressure distribution used in this study corresponded to a location $5.1 \mathrm{~m}$ downstream of the nose cap on the centerline of the windward side of the NASA wingedbody reference vehicle, ${ }^{18}$ and will be discussed subsequently (Figs. 11 and 12). The peak heating corresponded to flight at an angle of attack of $40^{\circ}$. The transient thermal test was conducted in a gaseous nitrogen environment. A more detailed description of the steady state and transient thermal testing apparatus is provided in Ref. 13 .

\section{$\underline{\text { Analytical Model Development }}$}

In the absence of natural convection, the governing conservation of energy equation for the problem of combined radiation and conduction in a radiation participating media bounded by two solid surfaces at specified temperatures is given by: ${ }^{22}$

$$
\rho c \frac{\partial \mathrm{T}}{\partial \mathrm{t}}=\frac{\partial}{\partial \mathrm{x}}\left(\mathrm{k} \frac{\partial \mathrm{T}}{\partial \mathrm{x}}\right)-\frac{\partial \mathrm{q}_{\mathrm{r}}}{\partial \mathrm{x}}
$$

subject to the following initial and boundary conditions:

$$
\begin{gathered}
T(x, 0)=T_{0}(x) \\
T(0, t)=T_{1}(t) \\
T(L, t)=T_{2}(t)
\end{gathered}
$$

Here $T_{o}$ is the initial temperature, and $T_{1}$ and $T_{2}$ are the transient specified temperatures on the boundaries.

The modified two-flux approximation was used for modeling the radiation heat transfer in the participating media because the uncertainty in radiative properties over the temperature range of interest did not warrant use of more detailed models. Furthermore, even though typical fibrous insulations for thermal protection systems are of such thickness to be optically thick, the goal of the present study was to develop a model that can be used for both optically thick fibrous insulations and for very thin fibrous insulation spacers used in high temperature multiplayer insulations ${ }^{12}$ that do not fall in the optically thick category. Assuming a gray medium, in the modified two-flux approximation the radiant flux is assumed to be composed of the forward and backward radiative fluxes:

$$
\mathrm{q}_{\mathrm{r}}=\mathrm{F}^{+}-\mathrm{F}^{-}
$$

where the forward and backward radiative fluxes are governed by:

$$
\begin{aligned}
\frac{1}{\sqrt{3} \beta} \frac{\partial \mathrm{F}^{+}}{\partial \mathrm{x}} & =-[1-\omega(1-\mathrm{b})] \mathrm{F}^{+}+\mathrm{b} \omega \mathrm{F} \\
& +(1-\omega) \mathrm{n}^{2} \sigma \mathrm{T}^{4} \\
-\frac{1}{\sqrt{3} B} \frac{\partial \mathrm{F}^{-}}{\partial \mathrm{x}} & =-[1-\omega(1-\mathrm{b})] \mathrm{F}+b \omega \mathrm{F}^{+} \\
& +(1-\omega) \mathrm{n}^{2} \sigma \mathrm{T}^{4}
\end{aligned}
$$

This formulation assumes anisotropic scattering and has been used by Domoto and Wang ${ }^{23}$ for radiative transfer in gases with nonisotropic particle scattering, and by Mathews, et al, ${ }^{24}$ for solving the combined conduction and radiation heat transfer in porous materials. Assuming that the bounding solid surfaces are diffuse emitting/reflecting surfaces, the radiant boundary conditions are: 


$$
\begin{aligned}
& \mathrm{F}^{+}(0)=\varepsilon_{1} \mathrm{n}^{2} \sigma \mathrm{T}_{1}^{4}+\left(1-\varepsilon_{1}\right) \mathrm{F}^{-}(0) \\
& \mathrm{F}^{-}(\mathrm{L})=\varepsilon_{2} \mathrm{n}^{2} \sigma \mathrm{T}_{2}^{4}+\left(1-\varepsilon_{2}\right) \mathrm{F}^{+}(\mathrm{L})
\end{aligned}
$$

where the subscripts 1 and 2 refer to the bounding surfaces at $\mathrm{x}=0$ and $\mathrm{x}=\mathrm{L}$, respectively. The governing equations and boundary conditions given in Eqs. (6) and (7) constitute a system of first order differential equations. Manipulation of Eqs. (6) and (7) to eliminate $\mathrm{F}^{-}$yielded the following second order differential equation and boundary conditions for the forward radiative flux:

$$
\begin{aligned}
& \frac{\partial^{2} \mathrm{~F}^{+}}{\partial \mathrm{x}^{2}}=3 \beta^{2}\left\{[1-\omega(1-\mathrm{b})]^{2}-\mathrm{b}^{2} \omega^{2}\right\} \mathrm{F}^{+} \\
&-3 \beta^{2}(1-\omega)[1-\omega(1-2 \mathrm{~b})] \mathrm{n}^{2} \sigma \mathrm{T}^{4} \\
&+4 \sqrt{3} \beta(1-\omega) \mathrm{n}^{2} \sigma \mathrm{T}^{3} \frac{\partial \mathrm{T}}{\partial \mathrm{x}} \\
& \frac{1}{\sqrt{3} \beta} \frac{\partial \mathrm{F}^{+}}{\partial \mathrm{x}}+\left[1-\omega(1-\mathrm{b})-\frac{\mathrm{b} \omega}{1-\varepsilon_{1}}\right] \mathrm{F}^{+}= \\
& \mathrm{n}^{2} \sigma \mathrm{T}_{1}^{4}\left(1-\omega-\frac{\varepsilon_{1} b \omega}{1-\varepsilon_{1}}\right) \\
& \frac{1}{\sqrt{3} \beta} \frac{\partial \mathrm{F}^{+}}{\partial \mathrm{x}}+\left[1-\omega(1-\mathrm{b})-\mathrm{b} \omega\left(1-\varepsilon_{2}\right)\right] \mathrm{F}^{+}= \\
& \mathrm{n}^{2} \sigma \mathrm{T}_{2}^{4}\left(1-\omega+\mathrm{b} \omega \varepsilon_{2}\right)
\end{aligned}
$$

where Eqs. 8.b and 8.c are applicable at $x=0$ and $x=L$, respectively. Once the distribution of the forward radiative flux is obtained from solving the above equations, the backward radiative flux is obtained from:

$$
\mathrm{F}^{-}=\frac{1}{\mathrm{~b} \omega}\left\{\begin{array}{l}
\frac{1}{\sqrt{3} \beta} \frac{\partial \mathrm{F}^{+}}{\partial \mathrm{x}}+[1-\omega(1-\mathrm{b})] \mathrm{F}^{+} \\
-(1-\omega) \mathrm{n}^{2} \sigma \mathrm{T}^{4}
\end{array}\right\}
$$

The extinction coefficient is related to the specific extinction coefficient through: ${ }^{25}$

$$
\beta=e \rho
$$

while the optical thickness is related to the extinction coefficient through: ${ }^{22}$

$$
\tau_{0}=ß \mathrm{~L}
$$

The albedo of scattering, $\omega$, specific extinction coefficient, $e$, and the backscattering fraction, $b$, were not known and were determined using the parameter estimation technique described subsequently. The index of refraction, $n$, was assumed to be unity. This assumption was also used by Marschall, et al., ${ }^{26}$ in analyzing radiation transport through rigid ceramic insulations. In a high porosity medium the effective index of refraction should be dominated by the index of refraction of the void space.

Gas thermal conductivity does not vary with pressure but the exchange of heat from gas molecules to bounding solid surfaces is influenced by the environmental pressure in the rarefied and transition flow transport regimes. Thus, an effective gas thermal conductivity was defined as: $:^{27}$

$$
\mathrm{k}_{\mathrm{g}}=\frac{\mathrm{k}_{\mathrm{g}}^{*}}{\Phi+2 \Psi \frac{2-\alpha}{\alpha} \frac{2 \gamma}{\gamma+1} \frac{1}{\operatorname{Pr}} \mathrm{Kn}}
$$

which relates the effective gas thermal conductivity at various pressures to the gas thermal conductivity at atmospheric pressure, $\mathrm{k}_{\mathrm{g}}{ }^{*}$. The parameters $\Phi$ and $\Psi$ depend on the Knudsen number. $\Phi=1, \Psi=0$ for Knudsen number less than 0.01 (continuum regime), $\Phi$ $=1, \Psi=1$ for Knudsen number between 0.01 and 10 (transition regime), and $\Phi=0, \Psi=1$ for Knudsen number greater than 10 (free-molecular regime). The thermal accommodation coefficient for interchange between nitrogen gas and alumina fibers was assumed to be unity. The Knudsen number, $K n$, is calculated from: ${ }^{27}$

$$
\mathrm{Kn}=\frac{\lambda}{\mathrm{L}_{\mathrm{c}}}
$$

The gas molecular mean free path, $\lambda$, is given by: ${ }^{28}$

$$
\lambda=\frac{\mathrm{K}_{\mathrm{B}} \mathrm{T}}{\sqrt{2} \pi \mathrm{d}_{\mathrm{g}}^{2} \mathrm{P}}
$$

The characteristic length, $L_{c}$, for gas conduction in fibers having a diameter $D_{f}$ is defined as: ${ }^{3}$

$$
\mathrm{L}_{\mathrm{c}}=\frac{\pi}{4} \frac{\mathrm{D}_{\mathrm{f}}}{\mathrm{f}}
$$

The solid fraction ratio, $f$, is defined as the ratio of density of fibrous insulation to the density of fiber parent material.

Theoretical modeling of solid conduction through fibers and points of contact between them is difficult, and various empirical relations have been developed to model the solid conduction. The empirical model used in this study was:

$$
\mathrm{k}_{\mathrm{s}}=\mathrm{f}^{\mathrm{m}} \mathrm{k}_{\mathrm{s}}^{* *}
$$

which relates the solid thermal conductivity of fibrous insulation to the thermal conductivity of the fiber parent material (alumina), $\mathrm{k}_{\mathrm{s}}{ }^{* *}$. The exponent $m$ was determined using the parameter estimation technique in the present study. This model is based on the model proposed by Verschoor, et al., ${ }^{3}$ The exponent value of 2 was previously utilized for modeling solid conduction in fibrous insulation spacers in high temperature 
multilayer insulations, ${ }^{12}$ but for the present investigation it was decided to estimate the value of the exponent in order to better fit the data instead of arbitrarily setting it at 2 .

Different ways of modeling the interaction between solid and gas conduction have been used by various researchers. The parallel thermal network model has been used for modeling heat transfer in rigid $^{28}$ and loose fibrous insulations: ${ }^{12}$

$$
\mathrm{k}=\mathrm{fk}_{\mathrm{s}}+(1-\mathrm{f}) \mathrm{k}_{\mathrm{g}}
$$

A combined parallelseries thermal network has also been used in rigid ${ }^{6}$ and loose fibrous insulations: ${ }^{11}$

$$
\begin{aligned}
\mathrm{k} & =\mathrm{A}\left\{\mathrm{fk}_{\mathrm{s}}+(1-\mathrm{f}) \mathrm{k}_{\mathrm{g}}\right\} \\
& +(1-\mathrm{A})\left\{\frac{\mathrm{k}_{\mathrm{s}} \mathrm{k}_{\mathrm{g}}}{(1-\mathrm{f}) \mathrm{k}_{\mathrm{s}}+\mathrm{fk}_{\mathrm{g}}}\right\}
\end{aligned}
$$

where $A$ and ( $1-A)$ are the fractions of heat transfer in parallel and series mode, respectively. Lee and Cunnington have used the following formulation for rigid fibrous insulation: ${ }^{2}$

$$
\mathrm{k}=\mathrm{f} \rho_{\mathrm{s}}^{\mathrm{m}} \mathrm{k}_{\mathrm{s}}+\mathrm{k}_{\mathrm{g}}
$$

Hager and Steere used a combination of solid conduction with a series thermal network for gas/solid conduction: ${ }^{4}$

$$
\mathrm{k}=4 \mathrm{f}^{3} \mathrm{k}_{\mathrm{s}}+\frac{\mathrm{k}_{\mathrm{s}} \mathrm{k}_{\mathrm{g}}}{(1-\mathrm{f}) \mathrm{k}_{\mathrm{s}}+\mathrm{fk} \mathrm{g}}
$$

Bhattacharyya developed a different model for combining solid and gas conduction: ${ }^{7}$

$$
\mathrm{k}=\mathrm{k}_{\mathrm{s}}+\frac{\mathrm{k}_{\mathrm{g}}-\mathrm{k}_{\mathrm{s}}}{1+\frac{\mathrm{f}}{1-\mathrm{f}}\left[1+\mathrm{z} \frac{\mathrm{k}_{\mathrm{g}}-\mathrm{k}_{\mathrm{s}}}{\mathrm{k}_{\mathrm{g}}+\mathrm{k}_{\mathrm{s}}}\right]}
$$

with $z=1$ when all the fibers are perpendicular to the direction of heat flow, $z=2 / 3$ for random fiber orientation, and $z=5 / 6$ for half of fibers being random and the other half being normal to the direction of heat flow.

The criteria used for deciding which form to use for modeling the gas/solid conduction interaction were that the model should be dimensionally consistent and should reduce to $k_{s}{ }^{* *}$ when $f=1$, and to $k_{g}$ when $f=0$. The only two models that could meet these criteria were the parallel model [Eq. (17. a)] and Bhattacharyya's model [Eq. (17.e)], with the solid conduction term defined in Eq. (16). These two models were evaluated in this study.

The finite volume form of the conservation of energy equation, Eq. (2), was solved using an explicit time marching formulation. Constant temperature boundary conditions were used for specifying data from the steady-state thermal conductivity measurements, while temporally varying boundary conditions were used for specifying the data from the transient therma 1 test. At each time step, the governing equation and boundary conditions for the forward radiative flux, Eqs. (8.a) - (8.c), were solved using a finite difference technique using the predicted temperature distribution in the medium from the previous time step solution of conservation of energy equation. The backward radiative flux distribution was then obtained from Eq. (9). Second order finite difference approximations were used for the first order derivatives in Eqs. (8) (9). The radiant flux calculated from Eq. (5) was then used in Eq. (2) to obtain temperature distributions for the following time step. For modeling the steady-state test results the physical domain was discretized using 161,321 , and 481 nodes for sample thicknesses of 13.3, 26.6 and $39.9 \mathrm{~mm}$, respectively. For modeling the transient test results 160 nodes were used in the 53.3 $\mathrm{mm}$ thick fibrous insulation sample located between the septum and aluminum panels, while 40 nodes were used in the $24.3 \mathrm{~mm}$ thick fibrous insulation sample located between the aluminum panel and the watercooled plate. To study the adequacy of the numerical model mesh, the total number of nodes was doubled. The difference between the predictions of aluminum panel temperature for the transient thermal tests using the two different nodal spacings was less then $0.1 \mathrm{~K}$.

\section{Parameter Estimation}

The specific extinction coefficient, albedo of scattering, backscattering fraction, and the solid conduction exponent term were not known and were estimated using parameter estimation techniques. The estimation strategy was based on least-squares minimization of the difference between measured and predicted effective thermal conductivities for the fibrous insulation samples with a density of $24 \mathrm{~kg} / \mathrm{m}^{3}$ and at environmental pressures of $1.33 \times 10^{-4}$ and 99.98 $\mathrm{kPa}$ :

$$
\mathrm{S}=\sum_{\mathrm{i}=1}^{\eta}\left[\mathrm{k}_{\mathrm{e}-\mathrm{m}}(\mathrm{i})-\mathrm{k}_{\mathrm{e}-\mathrm{p}}(\mathrm{i}, \mathrm{e}, \omega, \mathrm{b}, \mathrm{m})\right]^{2}
$$

subject to the following physical constraints:

$$
\begin{gathered}
\mathrm{e} \geq 0 \\
0 \leq \mathrm{b} \leq 1 \\
0 \leq \omega \leq 1
\end{gathered}
$$

The total number of samples used in the parameter estimation routine, $\eta$, was 36 . It was assumed that the 
albedo of scattering and backscattering fraction are independent of temperature, while the specific extinction coefficient was a linear function of temperature:

$$
\mathrm{e}=\mathrm{e}_{0}+\mathrm{e}_{1} \mathrm{~T}
$$

Therefore a total of 5 parameters $\left(\mathrm{m}, \mathrm{b}, \omega, \mathrm{e}_{\mathrm{o}}, \mathrm{e}_{1}\right)$ needed to be estimated.

The genetic algorithm optimization routine was used for finding the set of parameters that minimized the objective function in Eq. 18, subject to the constraints provided in Eqs. (19.a)- (19.c). Genetic algorithm optimization is a non-gradient based optimization method that is built upon natural selection mechanisms, and is described in detail elsewhere. ${ }^{29,30}$

\section{$\underline{\text { Results and Discussion }}$}

Typical steady-state thermal conductivity measurements are discussed. The thermal conductivity data with the two heating orientations for studying natural convection are presented. The results of the genetic algorithm parameter estimation are discussed. The comparison of predicted and measured thermal conductivity data and the transient test results are presented.

\section{Steady-State Test Results}

The effective thermal conductivity of fibrous insulation samples 1-7 as a function of temperature difference across the samples for an environmental pressure of $1.33 \times 10^{-4} \mathrm{kPa}$ is shown in Fig. 4. Error bars representing the average overall uncertainty of $\pm 7.5 \%$ are shown for the $26.6 \mathrm{~mm}$ thick samples at densities of 24 and $48 \mathrm{~kg} / \mathrm{m}^{3}$. At this pressure gas conduction was negligible; therefore, the effective thermal conductivity comprised of contributions due to solid conduction and radiation heat transfer. The effective thermal conductivity varied non-linearly with temperature difference across the sample, increasing rapidly with increasing temperature due to the nonlinear radiation heat transfer. This effect was more pronounced with the lower density insulation, where radiation heat transfer was more dominant. The effective thermal conductivity decreased with increasing insulation density. As the density increased the solid conduction contribution increased, but the radiation heat transfer decreased more rapidly, resulting in a net decrease in the effective thermal conductivity. Furthermore, the effective thermal conductivity does not appear to vary with sample thickness to within the experimental uncertainty range.
The variation of effective thermal conductivity with environmental pressure for fibrous insulation sample with density of $48 \mathrm{~kg} / \mathrm{m}^{3}$ and thickness of 26.6 $\mathrm{mm}$ is shown in Fig. 5. Data are plotted for three different nominal temperature differences across the sample: 240, 730 and $940 \mathrm{~K}$. The measured effective thermal conductivity increases with increasing pressure. Gas conduction is almost negligible below $1.33 \times 10^{-4}$ $\mathrm{kPa}$ where the gas is in a free molecular rarefied state. Gas conduction rapidly increases between $1.33 \times 10^{-2}$ and $1.33 \mathrm{kPa}$ where the gas goes through a transition region between free molecular and continuum states, and then stays relatively constant between 13.33 and $101.32 \mathrm{kPa}$ where the gas is in a continuum state. The same trends were observed in all the other samples.

\section{Natural Convection}

To determine the effect of natural convection, the variation of effective thermal conductivity with the applied heating orientation, aligned or opposite to gravity, for insulation samples at a density of $24 \mathrm{~kg} / \mathrm{m}^{3}$ and at thicknesses of 26.6 and $39.9 \mathrm{~mm}$ are shown in Figs 6.a and 6.b, respectively. Data are plotted as effective thermal conductivity versus temperature difference across the sample for environmental pressures of 0.133 and $99.99 \mathrm{kPa}$. If natural convection is a feasible mode of heat transfer in these fibrous insulations, it should manifest itself in the data with the applied heating opposite to the gravity vector, and should result in higher effective thermal conductivities compared to tests with the applied heating aligned with the gravity vector. Furthermore, natural convection is more likely to occur at the insulation density of 24 $\mathrm{kg} / \mathrm{m}^{3}$ which is the lowest density and highest porosity sample tested in the present study. The data in figs. 6 a and $6 \mathrm{~b}$ indicate that within the experimental uncertainty range $( \pm 7.5 \%)$ there is no difference between measurements at the two orientations, even at $1000 \mathrm{~K}$ temperature differences maintained across the sample thickness. This observation verifies that natural convection is not a mode of heat transfer for fibrous insulation samples with densities equal to or greater than $24 \mathrm{~kg} / \mathrm{m}^{3}$.

\section{Validation of Numerical Model: Steady State $\underline{\text { Results }}$}

For simulating steady state thermal tests a linearly varying initial temperature distribution was assumed throughout the insulation thickness between the measured hot and cold side temperatures. The solution of the transient conservation of energy equation was marched in time till a steady-state condition was 
achieved, and then, the effective thermal conductivity was calculated from the Fourier's law of heat conduction using the calculated total steady-state heat flux (including contributions of both radiative and conductive heat fluxes) and the imposed temperature difference across the medium according to Eq. 1.

The genetic algorithm parameter estimation technique was utilized to estimate the radiant and conduction parameters needed $\left(\mathrm{m}, \mathrm{b}, \omega, \mathrm{e}_{\mathrm{o}}, \mathrm{e}_{1}\right)$. Parameter estimation was conducted using both the parallel network model [Eq. (17.a)] and

Bhattacharyya's model [Eq. (17.e)] with $z=5 / 6$ for modeling gas/solid conduction interaction. The parameter estimation was based on minimizing the sum of the square of differences between measured and predicted effective thermal conductivities for fibrous insulation data at a density of $24 \mathrm{~kg} / \mathrm{m}^{3}$. Data at pressures of $1.33 \times 10^{-4}$ and $99.98 \mathrm{kPa}$, at three sample thicknesses of 13.3, 26.6, and $39.9 \mathrm{~mm}$, and various temperature differences $(7,7$, and 4 temperature differences for sample thicknesses of 13.3, 26.6, and $39.9 \mathrm{~mm}$, respectively) were used, resulting in a total of 36 data points. The results of the parameter estimation for both models are presented in Table 2. The parameters, the sum of the square of differences, $S$, and the root mean square deviation, $R$, are presented. The root mean square deviation is obtained from:

$$
\mathrm{R}=\sqrt{\frac{\mathrm{S}}{\eta}}
$$

Two root mean square deviations are presented in Table 2. $R_{1}$ is for the samples used in the parameter estimation (36 data points), while $\mathrm{R}_{2}$ is for all the data points used in the study including the data points used in the parameter estimation (443 data points). $R_{1}$ is indicative of how good a fit has been obtained for data at a density of $24 \mathrm{~kg} / \mathrm{m}^{3}$ and at pressures of $1.33 \times 10^{-4}$ and $99.98 \mathrm{kPa}$, while $\mathrm{R}_{2}$ is indicative of how good the model and estimated parameters apply over all densities, pressures and temperature differences. Both solid/gas conduction interaction mo dels yielded similar results with Bhattacharyya's model [Eq. (17.e)] yielding slightly better results based on the tabulated root mean square deviations. The results indicate that the alumina fibrous insulation evaluated in this study is highly scattering $(\omega \geq 0.97)$, and strongly forward scattering $(\xi=1-b \geq 0.72)$.

The comparison of measured and predicted effective thermal conductivities for the $13.3 \mathrm{~mm}$ thick sample at a density of $24.2 \mathrm{~kg} / \mathrm{m}^{3}$ is provided in Fig. 7 . Data are presented as effective thermal conductivity versus pressure for temperature differences of 247, 572, and $938 \mathrm{~K}$ maintained across sample thickness. It should be noted that the numerical data were forced to fit the experimental data at the extreme high and low pressure points at this insulation density using the genetic algorithm parameter estimation. The numerical data using the two different gas/solid conduction interaction models almost coincide, and generally match the experimental measurements to within the $\pm 7.5 \%$ experimental uncertainty. The comparison of measured and predicted effective thermal conductivities for the $26.6 \mathrm{~mm}$ thick sample at a density of $48 \mathrm{~kg} / \mathrm{m}^{3}$ for temperature differences of 242,569 , and $941 \mathrm{~K}$ maintained across sample thickness is provided in Fig. 8. Fig. 9 shows the comparison of measured and predicted effective thermal conductivities for the 39.9 mm thick sample at a density of $72 \mathrm{~kg} / \mathrm{m}^{3}$ and for temperature differences of 566 and $947 \mathrm{~K}$ maintained across sample thickness. The predictions using both gas/solid interaction models for both insulation densities and at the thicknesses shown in Figs. 8 and 9 generally coincided with each other and matched the experimental data to within the $\pm 7.5 \%$ experimental uncertainty. Because no data from the measurements at densities of 48 and $72 \mathrm{~kg} / \mathrm{m}^{3}$ were used in the parameter estimation technique, the good agreement between the predicted and measured data indicates that the approximate formulations used in the study have produced satisfactory results.

To study the relative significance of radiative and conductive heat fluxes throughout the insulation thickness, the numerical model using the parallel model for gas/solid interaction was applied to a $39.9 \mathrm{~mm}$ thick fibrous insulation sample at a density of $48 \mathrm{~kg} / \mathrm{m}^{3}$ with hot and cold boundary temperatures of 1293 and $293 \mathrm{~K}$, respectively. The spatial variation of the ratio of steady-state radiative and conductive fluxes to the total heat flux throughout the thickness of fibrous insulation for pressures of $1.333 \times 10^{-5}, 0.133$, and $101.32 \mathrm{kPa}$ are shown in Figs. 10a, 10.b, and 10.c, respectively. Nondimensional distances, $x / L$, of zero and one correspond to hot and cold boundaries, respectively. At a pressure of $1.333 \times 10^{-5} \mathrm{kPa}$, radiation is the dominant mode of heat transfer. Conduction is negligible for $x / L$ up to 0.5 , and then gradually increases to $q / q_{T}=0.19$ at the cold boundary. At a pressure of $0.133 \mathrm{kPa}$, radiation is again the dominant mode of heat transfer at the hot boundary and its relative magnitude decreases with increasing distance from the hot boundary. At $x / L=$ 0.83 , radiation and conduction fluxes are equal. Gas conduction is the dominant mode of heat transfer in the range $0.83 \leq x / L \leq 1$. The same general trends are observed at a pressure of $101.32 \mathrm{kPa}$, with radiation and conduction fluxes being equal at $x / L=0.54$. As the pressure increases, the magnitude of the conduction heat flux increases throughout the whole domain, with the location where conduction flux surpasses the 
radiation flux moving closer to the insulation midplane from the cold boundary.

\section{Validation of Numerical Model: Transient Results}

A transient thermal test was conducted with fibrous insulation sample 10. The measured temporal variations of the chamber pressure and of the Inconel panel temperature that were achieved in simulating reentry conditions are shown in Figs. 11 and 12, respectively, along with the expected radiation equilibrium temperature and pressure histories corresponding to the reentry flight profile shown in Fig. 2. Data are plotted versus elapsed time from the initiation of atmospheric reentry heating. The measured pressures followed the expected flight pressure profile closely with the exception of elapsed time less than 300 $\mathrm{s}$, where the measured pressures were higher than the expected reentry flight profile pressures. The agreement between the measured temperatures and the expected reentry flight profile temperatures was good until $2300 \mathrm{~s}$, after which the measured temperatures deviated significantly from the expected flight profile. These differences were due to the fact that the high convective cooling rates for the expected flight profile at lower altitudes and subsonic speeds could not be duplicated in the ground-test vacuum chamber with passive cooling. The time variation of the measured temperatures on the water-cooled plate is shown in Fig. 13.

In simulating the ground test using the numerical model, the measured temporal variations of the Inconel panel and water-cooled plate temperatures from Figs. 12 and 13 were used for the boundary conditions, and the measured pressure values from Fig. 11 were used for gas conduction calculations. The parallel gas/solid conduction interaction model given in Eq. (17.a) was used. The predicted temperature of the aluminum panel located between fibrous insulation samples with thicknesses of 53.3 and $13.3 \mathrm{~mm}$ shown in Fig. 3 was used for validation purposes. The temporal variation of the predicted and measured aluminum panel temperatures are shown in Fig. 14. The maximum difference between the numerically predicted and ground-test measured temperatures was $8 \mathrm{~K}$, with a root mean square deviation of $4.8 \mathrm{~K}$. The temporal variation of the relative difference between predicted and ground-test measured aluminum panel temperatures is shown in Fig. 15. The maximum difference was $1.6 \%$, while the difference did not exceed $1.2 \%$ for elapsed times less than or equal to $2400 \mathrm{~s}$. The close agreement between measured and predicted aluminum panel temperatures validated the numerical model for predicting the transient thermal performance of the fibrous insulation subject to conditions similar to expected reentry aerodynamic heating profile.

\section{Concluding Remarks}

The effective thermal conductivity of an alumina fibrous insulations at densities of 24,48 , and $72 \mathrm{~kg} / \mathrm{m}^{3}$ and at thicknesses of 13.3, 26.6 and $39.9 \mathrm{~mm}$ was measured over a pressure range of $1.33 \times 10^{-5}-101.2$ $\mathrm{kPa}$, and subject to temperature differences of 100-1300 $\mathrm{K}$ maintained across the sample thickness. The fibrous insulation samples at a density of $24 \mathrm{~kg} / \mathrm{m}^{3}$ and thicknesses of 26.6 and 39.9 were tested with two different heating orientations to investigate natural convection effects: applied heat flux aligned or opposite to the gravity vector. It was found that for fibrous insulation samples at densities equal to or larger than 24 $\mathrm{kg} / \mathrm{m}^{3}$ natural convection was not present as a mode of heat transfer. A transient test simulating reentry aerodynamic heating conditions was also performed.

A numerical model was developed for modeling combined radiation/conduction heat transfer in high porosity, high-temperature fibrous insulation. The radiation heat transfer was modeled using a modified two-flux formulation assuming anisotropic scattering and gray media. The parallel model and Bhattacharyya's model ${ }^{7}$ were investigated for modeling gas/solid conduction interaction. A genetic algorithm parameter estimation technique was utilized in conjunction with measured effective thermal conductivities for fibrous insulation sample at a density of $24 \mathrm{~kg} / \mathrm{m}^{3}$ and at nominal pressures of $1.33 \times 10^{-4}$ and $99.98 \mathrm{kPa}$ to obtain the best fit for the unknown radiant and conduction parameters needed in the numerical solution. The differences between predicted and measured effective thermal conductivities for all the samples at densities of 24,48 , and $72 \mathrm{~kg} / \mathrm{m}^{3}$ and at all tested temperatures and pressures were typically within the $\pm 7.5 \%$ experimental uncertainty range. The two models used for modeling gas/solid conduction interaction yielded similar results.

The numerical heat transfer model was applied to the transient thermal test simulating reentry aerodynamic heating conditions. The maximum relative difference between the numerically predicted and ground-test measured temperatures on the aluminum panel, representing a launch vehicle structure, was $1.6 \%$. The close agreement between measured and predicted aluminum panel temperatures validated the numerical model for predicting the transient thermal performance of the fibrous insulation subject to conditions similar to expected reentry aerodynamic heating profile. 


\section{Acknowledgements}

The author would like to thank the following NASA Langley Research Center employees for their invaluable support: Wayne D. Geouge for fabrication and instrumentation of the test apparatus, Jeffrey R. Knutson for providing temperature and pressure controls for the tests and assisting in running the experiments, and Dr. Max L. Blosser for his guidance.

\section{References}

1. Blosser, M. L., Chen, R. R., Schmidt, I. H., Dorsey, J. T., Poteet, C. C., and Bird, R. K., "Advanced Metallic Thermal Protection System Development," AIAA Paper 2002-0504, January 2002.

2. Lee, S-C, and Cunnington, G. R., "Conduction and Radiation Heat Transfer in High Porosity Fiber Thermal Insulation," Journal of Thermophysics and Heat Transfer, Vol. 44, No. 2, 2000, pp.121136.

3. Verschoor, J. D., Greebler, P., and Manville, N. J., "Heat Transfer by Gas Conduction and Radiation in Fibrous Insulation," Journal of Heat Transfer, Vol. 74, No. 8, August 1952, pp. 961-968.

4. Hager, N. E., Jr., and Steere, R. C., "Radiant Heat Transfer in Fibrous Thermal Insulation," Journal of Applied Physics, Vol. 38, No. 12, 1967, pp. 46634668.

5. Bankvall, C., "Heat Transfer in Fibrous Materials," Journal of Testing and Evaluation, Vol. 1, No. 5, 1973, pp. 235-243.

6. Pawel, R. E., McElroy, D. L., Weaver, F. J., and Graves, R. S., "High Temperature Thermal Conductivity of a Fibrous Alumina Ceramic," Thermal Conductivity, 19, Ed. by David Yarbrough, Plenum, New York, 1985, pp. 301-313.

7. Bhattacharyya, R. K., "Heat Transfer Model for Fibrous Insulations," Thermal Insulation Performance, ASTM STP 718, ed. by D. L. McElroy and R. P. Tye, American Society for Testing and Materials, Philadelphia, PA, 1980, pp. 272-286.

8. Larkin, B. K., and Churchill, S. W., "Heat Transfer by Radiation through Porous Insulations," American Institute of Chemical Engineers Journal, Vol. 4, No. 5, 1959, pp. 467-474.

9. Tong, T. W., and Tien, C. L., "Radiative Heat Transfer in Fibrous Insulations-Part I: Analytical
Study," Journal of Heat Transfer, Vol. 105, February 1983, pp. 70-75.

10. Tong, T. W., Yang, Q. S., and Tien, C. L., "Radiative Heat Transfer in Fibrous InsulationsPart II: Experimental Study," Journal of Heat Transfer, Vol. 105, February 1983, pp. 76-81.

11. Daryabeigi, K., "Analysis and Testing of High Temperature Fibrous Insulation for Reusable Launch Vehicles," AIAA Paper 99-1044, January 1999.

12. Daryabeigi, K., "Thermal Analysis and Design of Multi-layer Insulation for Re-entry Aerodynamic Heating." AIAA Paper 2001-2834, June 2001.

13. Daryabeigi, K., "Design of High Temperature Multi-layer Insulation, " Ph.D. Dissertation, University of Virginia, Charlottesville, VA, May 2000.

14. Stark, C., and Fricke, J., "Improved Heat-transfer Models for Fibrous Insulations," International Journal of Heat and Mass Transfer, Vol. 36, No. 3, 1993, pp. 617-625.

15. Tye, R. P., and McLaughin, E., "Theory of Thermal Conductivity of Fluids," Thermal Conductivity, Vol. 2, Academic Press, London, 1969.

16. Daryabeigi, K., "Effective Thermal Conductivity of High Temperature Insulations for Reusable Launch Vehicles," NASA TM-1999-208972, February 1999.

17. "Standard Test Method for Thermal Conductivity of Refractories," Annual Book of ASTM Standards, Vol. 15.01, American Society for Testing and Materials, West Conshohocken, PA, 2000, pp. 5459.

18. Access to Space Study-Advanced Technology Team (Option 3). Vol. III, Design Handbook, National Aeronautics and Space Administration, Washington, D.C., July 1993.

19. Ko, W. L., Quinn, R. D., and Gong, L., "FiniteElement Reentry Heat-transfer Analysis of Space Shuttle Orbiter,” NASA TP-2657, December 1986.

20. Blosser, M. L. "Investigation of Fundamental Modeling and Thermal Performance Issues for a Metallic Thermal Protection System Design," AIAA Paper 2002-0503, January 2002.

21. Thornton, E. A., Thermal Structures for Aerospace Applications, American Institute of Aeronautics and Astronautics, Reston, VA, 1996, p. 18.

22. Sparrow, E. M., and Cess, R. D., Radiation Heat 
Transfer, augmented ed., 1978, McGraw-Hill, New York, 1978, pp. 255-271.

23. Domoto, G. A., and Wang, W. C., "Radiative Transfer in Homogeneous Nongray Gases with Anisotropic Particle Scattering," Journal of Heat Transfer, Vol. 96, August 1974, pp. 385-390.

24. Matthews, L. K., Viskanta, R., and Incropera, F. P., "Combined Conduction and Radiation Heat Transfer in Porous Materials Heated by Intense Solar Radiation," Journal of Solar Energy Engineering, Vol. 107, February 1985, pp. 29-34.

25. Siegel, R., and Howell, J. R., Thermal Radiation Heat Transfer, $2^{\text {nd }}$ ed., 1981, McGraw-Hill, New York, 1981, pp. 426-427.

26. Marschall, J., Maddren, J., and Parks, J., "Internal Radiation Transport and Effective Thermal Conductivity of Fibrous Ceramic Insulation," AIAA 2001-2822, June 2001.

27. Gebhart, B., Heat Conduction and Mass Diffusion, McGraw-Hill, New York, pp. 442-444.

28. Williams, S. D., and Curry, D. M., "Predictions of Rigid Silica Based Insulation Conductivity," NASA TP-3276, January 1993.

29. Haupt, R. L., and Haupt, S .E., Practical Genetic Algorithms, 1998, Wiley, New York, 1998.

30. Garcia, S., Guynn, J., and Scott, E. P., "Use of Genetic Algorithms in Thermal Property Estimation: Part II - Simultaneous Estimation of Thermal Properties," Numerical Heat Transfer, Vol. 33, No. 2, 1998, pp. 149-168.
Table 1. Listing of fibrous insulation samples

\begin{tabular}{cccccc}
\hline \hline \multicolumn{2}{c}{$\begin{array}{c}\text { Sample } \\
\text { number }\end{array}$} & \multicolumn{4}{c}{ thickness, density, } \\
$\mathrm{mm}$ & $\mathrm{kg} / \mathrm{m}^{3}$ & $\begin{array}{c}\text { fraction } \\
\text { ratio }\end{array}$ & test & $\begin{array}{c}\text { heat } \\
\text { source } \\
\text { location }\end{array}$ \\
\hline 1 & 13.3 & 24.2 & 0.0073 & steady state & top \\
2 & 13.3 & 48.6 & 0.0147 & steady state & top \\
3 & 26.6 & 24.2 & 0.0073 & steady state & top \\
4 & 26.6 & 48 & 0.0145 & steady state & top \\
5 & 26.6 & 72 & 0.0218 & steady state & top \\
6 & 39.9 & 24.2 & 0.0073 & steady state & top \\
7 & 39.9 & 72 & 0.0218 & steady state & top \\
8 & 26.6 & 24.2 & 0.0073 & steady state & bottom \\
9 & 39.9 & 24.2 & 0.0073 & steady state & bottom \\
10 & 53.3 & 45.1 & 0.0137 & transient & top \\
\hline \hline
\end{tabular}

Table 2. Parameter estimation results.

\begin{tabular}{ccc}
\hline \hline parameters & $\begin{array}{c}\text { Parallel } \\
\text { model, } \\
\text { Eq. 17.a }\end{array}$ & $\begin{array}{c}\text { Bhattacharyya's } \\
\text { model, } \\
\text { Eq. 17.e }\end{array}$ \\
\hline$\omega$ & 0.97435 & 0.98818 \\
$\mathrm{~b}$ & 0.26821 & 0.27223 \\
$\mathrm{e}_{0}$ & 53.01689 & 53.15858 \\
$\mathrm{e}_{1}$ & 0.03879 & 0.03883 \\
$\mathrm{~m}$ & 1.46911 & 1.4386 \\
$\mathrm{~S}$ & $9.21 \times 10^{-4}$ & $9.15 \times 10^{-4}$ \\
$\mathrm{R}_{1}$ & $5.057 \times 10^{-3}$ & $5.042 \times 10^{-3}$ \\
$\mathrm{R}_{2}$ & $3.616 \times 10^{-3}$ & $3.462 \times 10^{-3}$ \\
\hline \hline
\end{tabular}




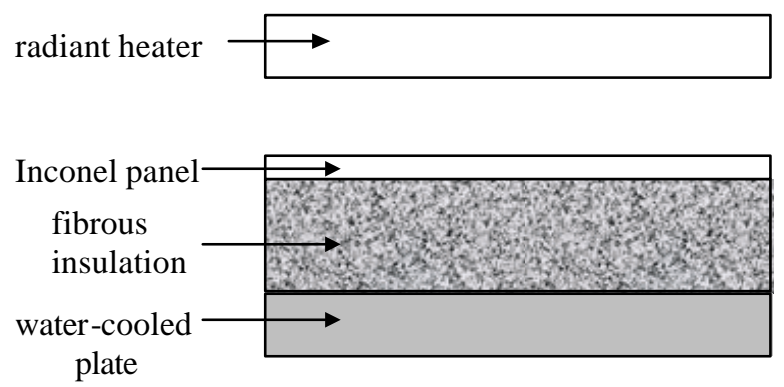

Fig. 1. Schematic of thermal conductivity test apparatus (not to scale).

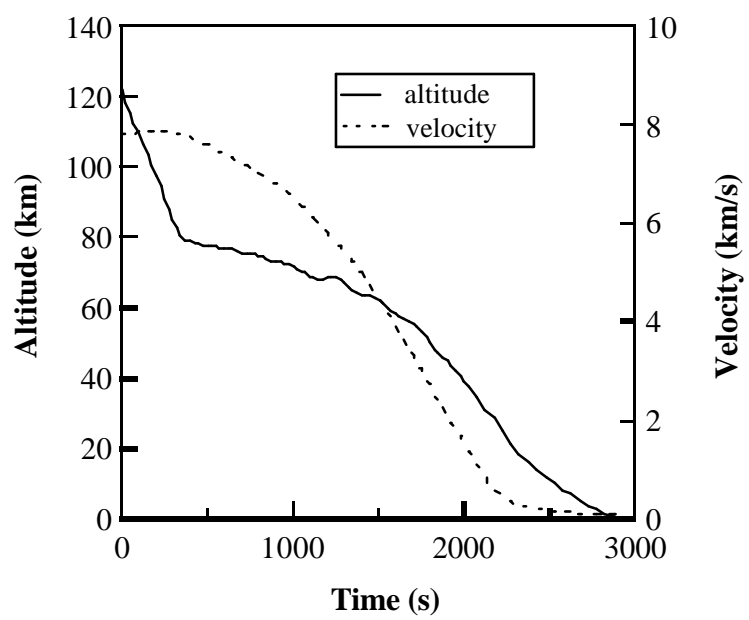

Fig. 2. Reentry flight profile.

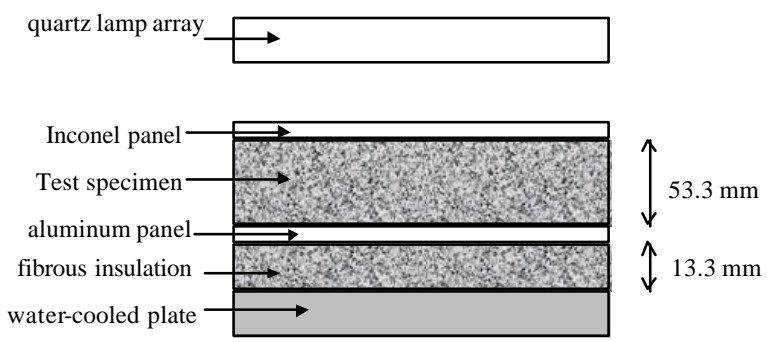

Fig. 3. Schematic of transient thermal test apparatus (not to scale).

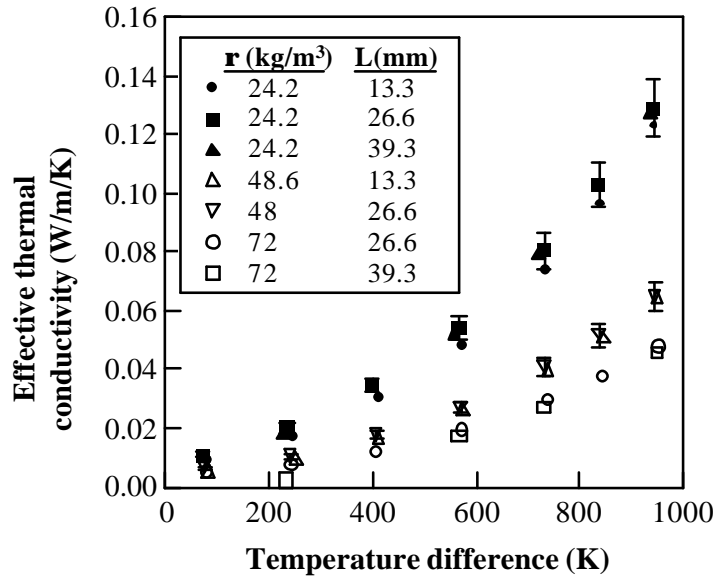

Fig. 4. Variation of effective thermal conductivity with temperature difference across sample thickness for various samples at $\mathrm{P}=1.33 \times 10^{-4} \mathrm{kPa}$.

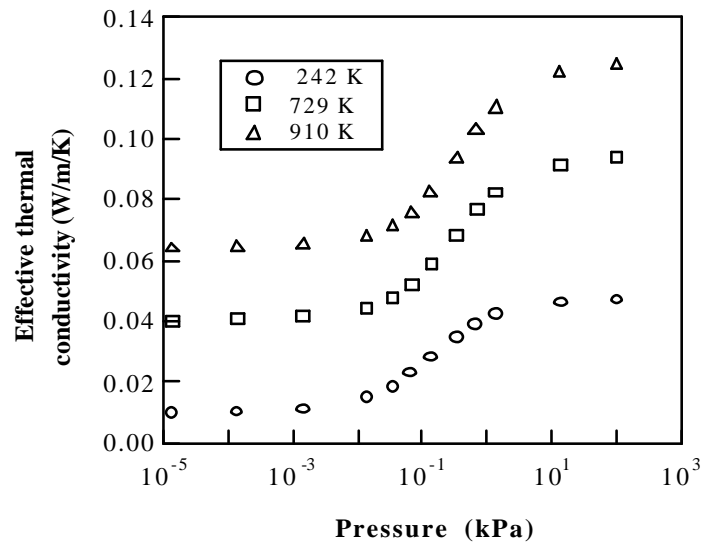

Fig. 5. Variation of effective thermal conductivity with pressure at three temperature differences across the sample for $\rho=48 \mathrm{~kg} / \mathrm{m}^{3}$ and $\mathrm{L}=26.6 \mathrm{~mm}$.

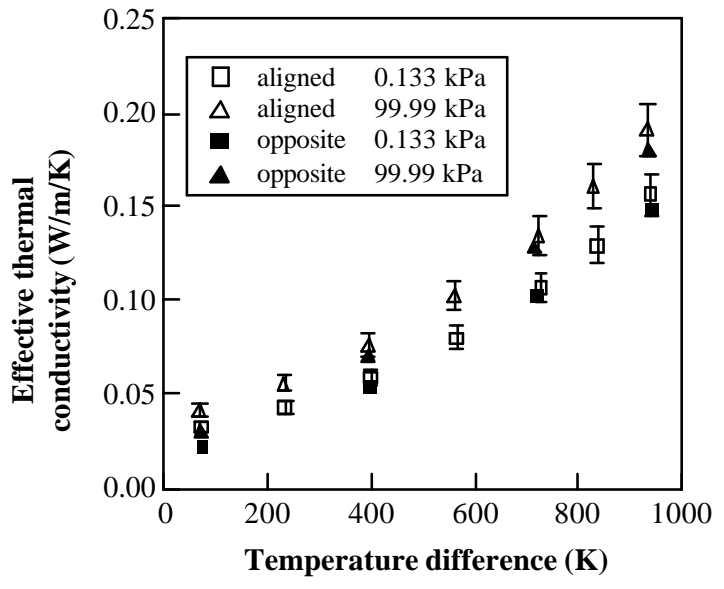

6.a

13

American Institute of Aeronautics and Astronautics 


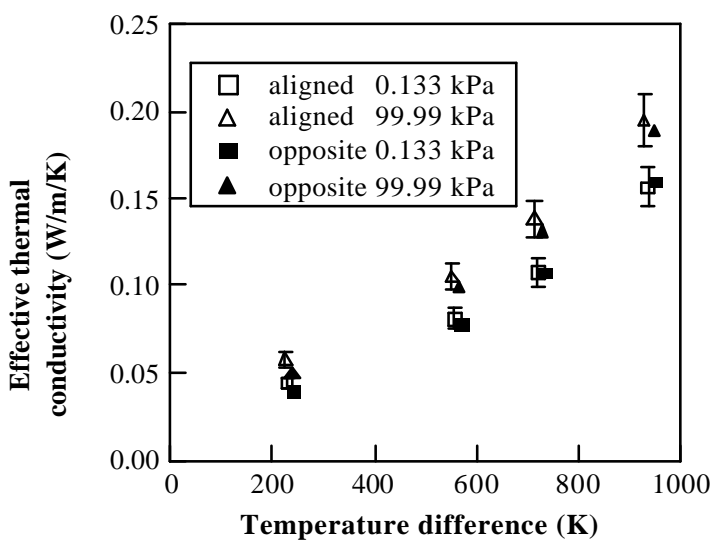

6.b

Fig. 6. Variation of effective thermal conductivity at two pressures and sample orientations for $\rho=24 \mathrm{~kg} / \mathrm{m}^{3}$; a) $\mathrm{L}=26.6 \mathrm{~mm}, \mathrm{~b}) \mathrm{L}=39.9 \mathrm{~mm}$.

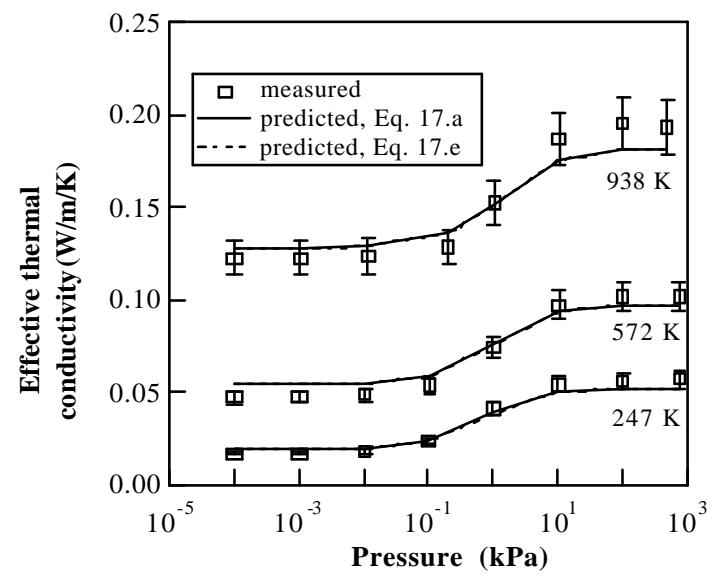

Fig. 7. Comparison of predicted and measured effective thermal conductivity for $\rho=24.2 \mathrm{~kg} / \mathrm{m}^{3}, \mathrm{~L}=$ $13.3 \mathrm{~mm}$.

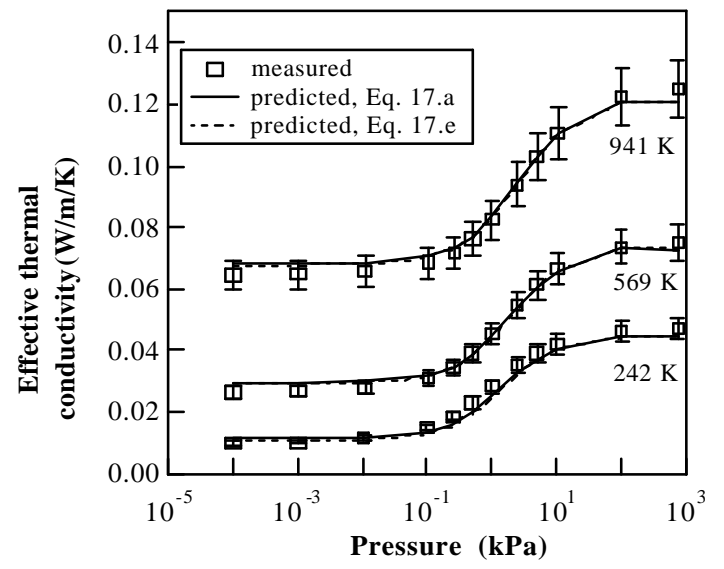

Fig. 8. Comparison of predicted and measured effective thermal conductivity for $\rho=48 \mathrm{~kg} / \mathrm{m}^{3}, \mathrm{~L}=$ $26.6 \mathrm{~mm}$.

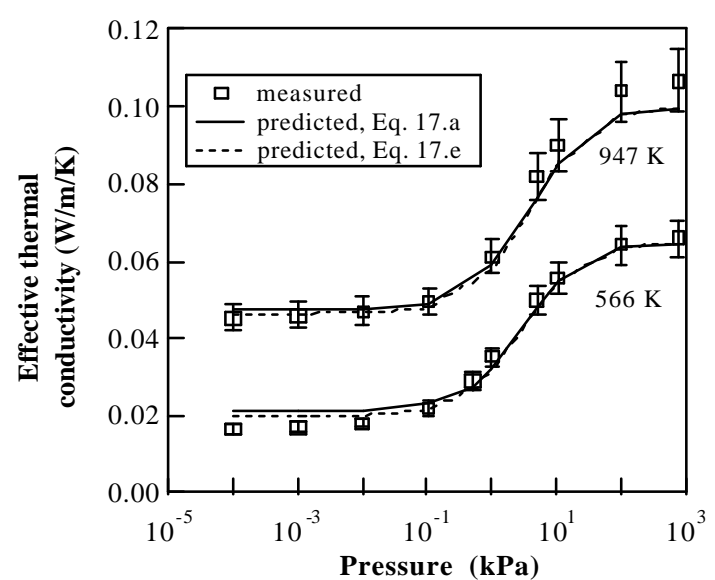

Fig. 9. Comparison of predicted and measured effective thermal conductivity for $\rho=72 \mathrm{~kg} / \mathrm{m}^{3}, \mathrm{~L}=$ $39.9 \mathrm{~mm}$.

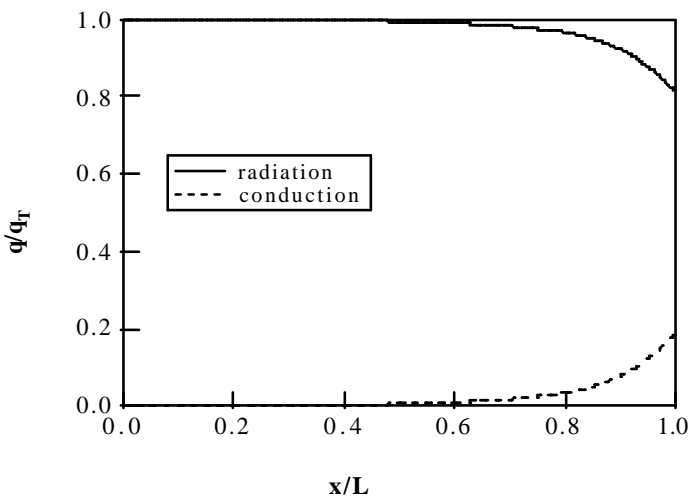

10.a

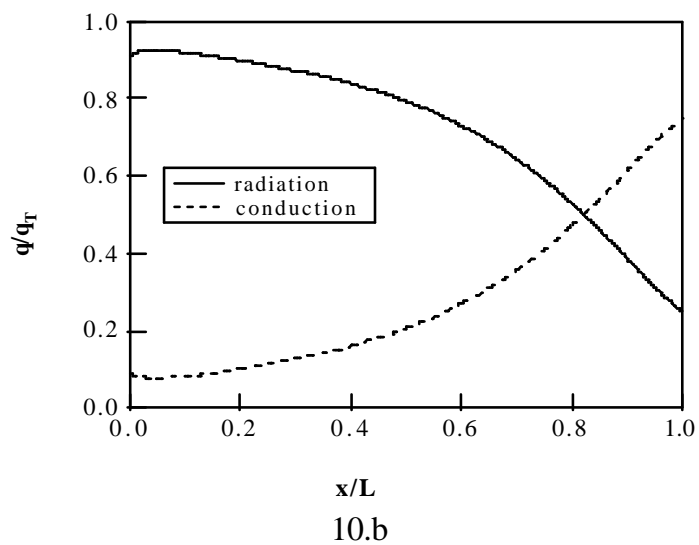




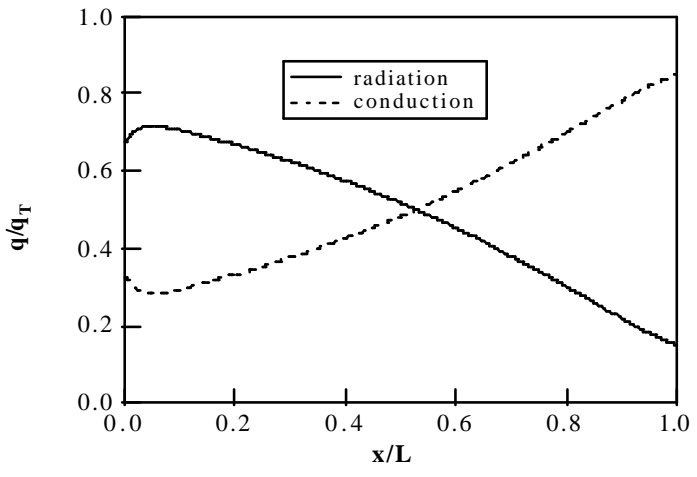

10.c

Fig. 10. Spatial variation of ratio of conduction and radiation fluxes to total heat flux at $\Delta \mathrm{T}=1000 \mathrm{~K}, \rho=48$ $\mathrm{kg} / \mathrm{m}^{3}, \mathrm{~L}=39.9 \mathrm{~mm}$ : a) $\left.\mathrm{P}=1.33 \times 10^{-5} \mathrm{kPa}, \mathrm{b}\right) \mathrm{P}=$ $0.133 \mathrm{kPa}, \mathrm{c}) \mathrm{P}=101.32 \mathrm{kPa}$.

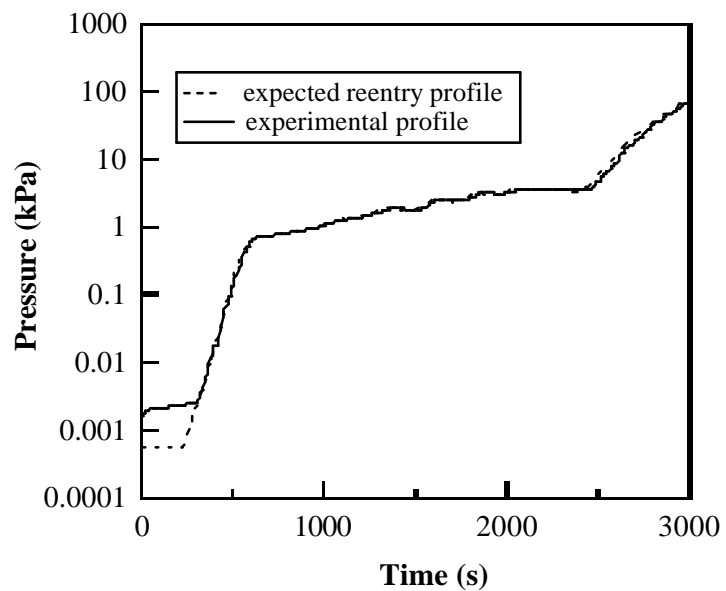

Fig. 11. Comparison of expected flight pressure history with ground-test measured pressure history.

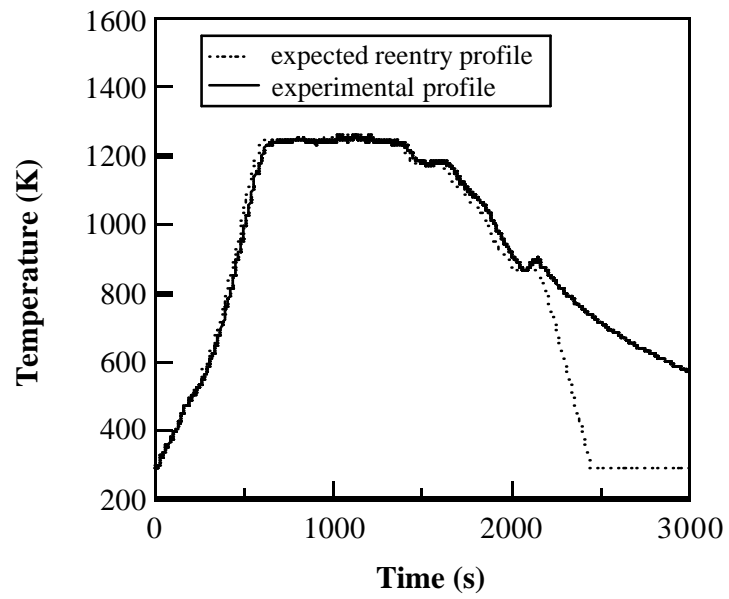

Fig. 12. Comparison of ground-test measured temperature on the Inconel panel with expected reentry radiation equilibrium temperature profile.

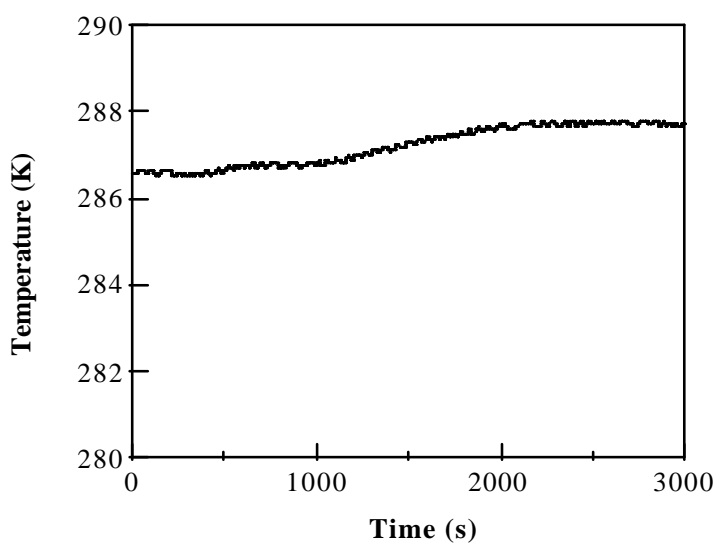

Fig. 13. Ground test-measured variation of watercooled plate temperature.

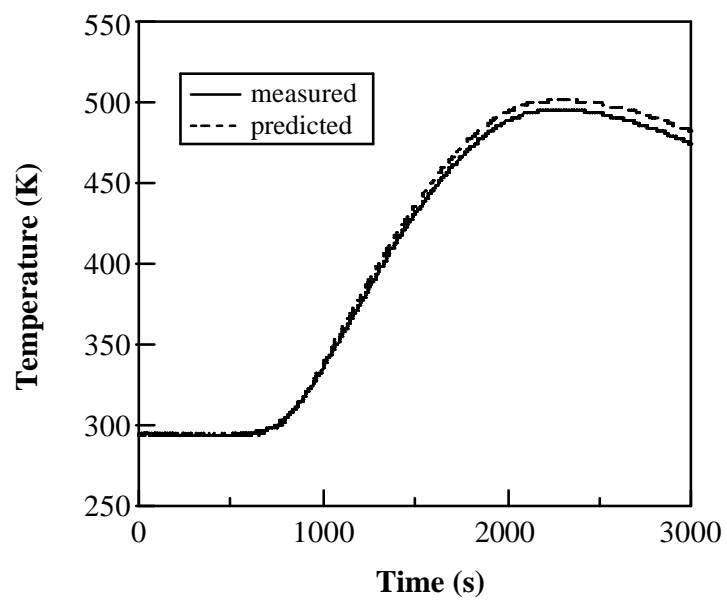

Fig. 14. Comparison of predicted and ground-test measured aluminum panel temperatures for transient insulation test.

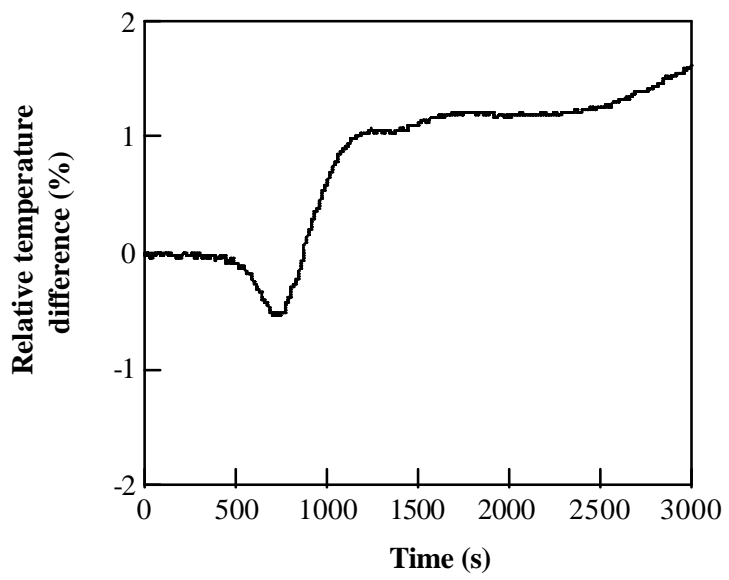

Fig. 15. Relative difference between predicted and ground-test measured aluminum panel temperatures for transient insulation test. 